\title{
LA POLÉMICA EN TORNO A LA BIBLIA REGIA DE ARIAS MONTANO
}

\author{
EMILIA FERNÁNDEZ TEJERO \\ NATALIO FERNÁNDEZ MARCOS \\ CSIC. Madrid
}

Si bien estamos familiarizados con las polémicas de los biblistas españoles del siglo XVI (teólogos versus filólogos, por ejemplo, León de Castro y Bartolomé de Medina versus Gaspar de Grajal, Martín Martínez de Cantalapiedra, Luis de León y Benito Arias Montano) menos difusión ha alcanzado la prolongación de estas polémicas hasta bien entrado el siglo XVII, en las que se vieron implicados al menos dos discípulos de Arias Montano.

Algo sabíamos ya de las dificultades que tuvo en Roma la aprobación de la Biblia Regia por, entre otros documentos, la carta que escribiera el cisterciense Luis de Estrada, abad de Santa María de Huerta, a su amigo Arias Montano ', y que la tormenta no remitió, como atestigua la inclusión de algunas obras de Arias Montano en los Indices Expurgatorios de 1607 y 1612, pese a haber sido él mismo el encargado de elaborar el Indice de Amberes de $1571^{2}$.

En el siglo XVII la polémica en torno a la obra de Arias Montano se personifica, por un lado, en Andrés de León, crítico feroz de la Biblia Regia, en especial de su edición del Targum o paráfrasis caldea, y por otro en Pedro de Valencia, discípulo, amigo y colaborador de Arias Montano, y Juan Moreno Ramírez, también discípulo y amigo de Arias Montano, y cuñado de Pedro de Valencia ${ }^{3}$.

${ }^{1}$ Cf. E. Fernández Tejero y N. Fernández Marcos, «Luis de Estrada y Arias Montano", Sefarad 42 (1982) 41-57.

2 J. A. JONES, "Pedro de Valencia's Defence of Arias Montano: The Expurgatory Indexes of 1607 (Rome) and 1612 (Madrid)", Bibliothèque d' Humanisme et Renaissance 40 (1987) 121-130 y J. M. DE BUjANDA, Index d'Anvers 1569, 1570, 1571, Quebec 1988, págs. 711-834.

${ }^{3}$ Cf. G. Morocho Gayo, "Trayectoria humanística de Pedro de Valencia: su actividad en la escuela de Zafra", en Actas del VII congreso español de Estudios 
Las fuentes más significativas para el estudio de esta polémica se conservan en dos voluminosos legajos de la Biblioteca Nacional de Madrid -502 (582 fols.) ${ }^{4}$ y 503 (829 págs.) - y un par de documentos breves -Escorial, ms. G-IV-32 (fols. 83v-85v), anónimo del siglo XVII, y British Museum, ms. Eg. 367, fol. 105r- estos dos últimos editados por $\mathbf{J}$. A. Jones 5 .

Andrés de León (1571-1642), zamorano, perteneció a la orden de los clérigos menores, en 1608 enseñó matemáticas en Sevilla y, según J. Rodríguez de Castro, pasó algunos años en Roma, en la casa de san Lorenzo

"y como en este tiempo se estudiaban en esta Casa con gran aplicacion las lenguas Orientales, Hebrea, Caldea, Griega, Arabiga, y Persa; con fundamento se cree, que el $\mathrm{P}$. León estudiase con perfeccion dichas Lenguas, baxo los Maestros mas acreditados que pagaba la Religion para instruir sus estudiantes» 6 .

Presumía, además, de poseer un ejemplar en siriaco que le había entregado el Papa Gregorio XIII, ejemplar en el que conservaba la auténtica paráfrasis caldea y que era favorable a la religión cristiana ?.

Pero en los informes recogidos en los citados manuscritos 502 y 503 de la Biblioteca Nacional la valoración de los conocimientos lingüísticos de Andrés de León y del original sobre el que basaba

Clásicos (Madrid, 20-24 de abril de 1987), III, Madrid 1989, 607-612; G. MoROCHO Gayo, "Introducción a una lectura de Pedro de Valencia", en J. Paniagua - F. J. y J. Fuente Fernández (eds.), Pedro de Valencia. Obras completas, vol. V, León 1993, 15-60, y J. L. Paradinas - R. González Cañal (eds.), Pedro de Valencia. Obras completas, vol. IV/1, León 1994.

${ }^{4}$ Sobre una parte de este manuscrito están basados los trabajos de J. A. Jones, "Las advertencias de Pedro de Valencia y Juan Ramírez acerca de la impresión de la "Paraphrasis Chaldaica" de la Biblia Regia", Bulletin Hispanique 84 (1982) 328-346 y "Censuras acerca de la impresión de la Paraphrasis Chaldaica de Andrés de León: un aspecto de la amistad entre Benito Arias Montano y Pedro de Valencia", en Homenaje a Pedro Sainz Rodríguez I: Repertorios, textos y comentarios, Madrid 1986, 339-348.

5 "Arias Montano and Pedro de Valencia", Bibliothèque d"Humanisme et Renaissance 38 (1976) 293-300, 297-300.

6 J. Rodríguez DE CASTRo, Biblioteca Española de los escritores rabinos españoles, I, Madrid 1781, págs. 529-536, 535; la cursiva es nuestra, por lo que analizaremos más adelante. Ver también los datos escuetos que recoge K. REINHARDT, Bibelkommentare spanischer Autoren (1500-1700) I, Madrid 1990, pág. 242.

7 J. Rodríguez de CASTRO, Biblioteca Española, págs. 532-533. 
sus correcciones a la Biblia Regia es muy otra; así, por ejemplo, ms. 503, pág. 321:

"Toda su obra tal cual es la haze el padre Andres de Leon con solos dos vocabularios el que esta impreso en el segundo tomo del aparato de la biblia Regia i otro que salio pocos años a i se intitula Pentaglotton ${ }^{8}$, i estos cita para provar sus versiones porque otra lecion de libros hebreos no la conoce ni aun (lo que peor es) entiende los diccionarios porque en el Pentaglotto que ai vocablos Hebreos Chaldeos, Syriacos, Arabigos el los tiene todos por chaldeos i toma unas veces unos i otras veces otros";

o pág. 443:

"Que el padre Andres de Leon no sepa la lengua hebrea, ni la griega ni la syriaca el mesmo lo confiesa i si digere que la sabe facilmente se convencera de lo contrario... Que no sepa pues la lengua Latina se colige candentemente de sus mesmos papeles en los cuales se hallan los ierros siguientes aput por apud / edictio por editio" ";

y en pág. 362:

"No tiene el padre Andres de Leon exemplar ninguno Chaldeo por cuya autoridad haga estas mundanças que haze. que no le tiene pruevase porque ni le muestra ni aun le alega. i porque no puede

${ }^{8}$ Probablemente se refiere al editado en Hannover, en 1612, por Valentin Schindler; cf. F. Vigouroux, Dictionnaire de la Bible, II, París 1912, col. 1416.

${ }^{9}$ En las págs. 571-572 se critican los daños que se siguen de alterar el texto por asociaciones meramente fonéticas y se traen a colación jocosamente algunos cambios que podrían introducirse con este método en el Evangelio mismo: «pusimos [en pág. 140] los de sermo et agnus es tu et dominum habes por Samaritanus es tu et daemonium habes [Juan 8,48]. i Salvator o Sanctus doctor por seductor [Mateo 27,63]. i frumenta por fragmenta [Juan 6,12]. Pero puedense añadir tantos i tan graves que muestren bien si es la invencion perniciosa i digna de gran correccion a cualquiera se le of receran muchos. pero aqui se pondran algunos... homo factus est si mudasse alguno homo fictus est vel homo falsus est... ne forte tumultus fieret in populo [Mateo 26,5] [por] ne forte tum ultus fieret in populo... estos exemplos bastan para mostrar el gran daño de esta invencion, pero notese que aun en estos no se quita letra ninguna pero si se quitasen muchas $i$ dicciones enteras $i$ renglones i no se cuidasse de la lengua ni de la gramatica della sino aviendolo cortado mudado juntado como a cada uno se le antojasse sin atencion a la construcion i propiedad de aquella lengua luego se tradugessen estos lugares en otra mas vulgar sin que se mostrasse de donde se tradugeron...". 
aver exemplar que contenga tantos errores en la lengua $i$ en la gramatica como se muestran desde la pag. 429 hasta la 445».

Sobre su mal uso de los diccionarios hemos encontrado diversos testimonios; por ejemplo, en el ms. 503, págs. 315ss, se refutan algunas de las correcciones propuestas por Andrés de León a la Biblia Regia. En Job 6,9b la Regia había traducido la paráfrasis caldea por "solvat manum suam", que Andrés de León corrige en «impleat manum suam»; y se explica a propósito de la raíz

«Leo sic impleat manum suam et paratum me reddat. nescio quomodo possit alio modo verti nisi mutetur $\Omega$ in 6 ... solvat, multo magis quam alia quaevis lectio vel versio vulgatae et lectioni et hebraeo textu respondet atque ideo si Leo utcumque possit Chaldaeum textum ad hebraeam vel vulgatam lectionem accomodare intendit cur hic sui inmemor aliter vertit? Pro יתר impleat manum suam non bene vertitur nam נתר Chald. marcescere et defluere significat et יתר abundare superesse relinqui et in aphel reliquum facere etc. unde non video quare vertit impleat nisi quando in dictionario sacri apparatus post radicem שרא solvere incipere etc. sequitur שיצי complevit consumavit, et fortasse haec omnia eiusdem radicis esse existimavit Leo et cum vellet significationem verbi שרא ponere posuit verbi שיצי;;

es decir, Andrés de León no sólo mudó de forma arbitraria la raíz יתר sino que, al consultar esta última raíz en el diccionario de la Regia, le atribuyó el significado de otra cercana: aplicó a la raíz שרא ("solvere») el significado de שיצי ("complere, consumare»).

Como hemos dicho, el punto principal de la polémica se centró en la edición de la paráfrasis caldea de la Biblia Regia. Como escribe J. A. Jones ${ }^{10}$, ya durante su estancia en Roma tenía concebido Andrés de León el proyecto de publicar una versión enmendada de esa paráfrasis; su idea no obtuvo demasiado eco en principio, pero al suscitarse la enemiga de los rabinos romanos contra su versión, la balanza pareció inclinarse a favor suyo:

"porque dezian los dichos Judios que con ellas se les quitavan las armas contra los Christianos, y esto fue causa para que fuesse oido

10 J. A. JONES, «Las advertencias», pág. 330. 
dicho padre i se començase a hacer caso de su obra, que hasta entonces no se avia hecho ninguno ni aun le querian oir".

Regresó a España, y en 1615 envió al Consejo Real una petición en la que afirmaba haber completado ya su paráfrasis; el Consejo remitió el proyecto, con poco entusiasmo, a la universidad de Alcalá.

J. A. Jones ha editado las censuras emitidas por dicha universidad " y comentado alguna de las objeciones de Andrés de León contra la paráfrasis de Arias Montano - justificativas de su propuesta de nueva edición-, así como las oportunas respuestas de Pedro de Valencia y Juan Moreno Ramírez.

A las censuras editadas por Jones podemos añadir dos colofones hebreos que se encuentran en el ms. 502, uno a favor y otro en contra de Andrés de León.

En el fol. 166v, con un hebreo incorrecto y con erratas que reproducimos literalmente, Juan Alvarez de Perea califica a León, tras haber examinado su obra «letra por letra, palabra por palabra", de «inteligente sabio" y conocedor del Targum "como su propia lengua», y aduce en su favor el testimonio "de dos sabios hebreos»; está fechado el 11 de abril de 1616:

אמרתי אני החתום למטה שראיתי המלכה אשר עשה החכם המשום הנבון איל פדרי אנדריש

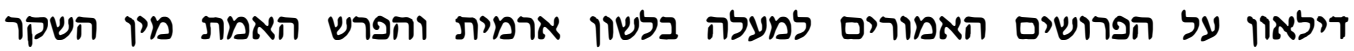

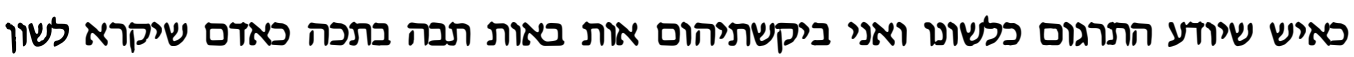

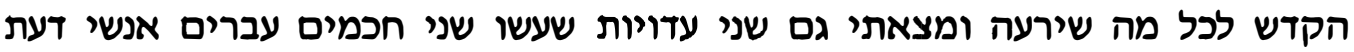

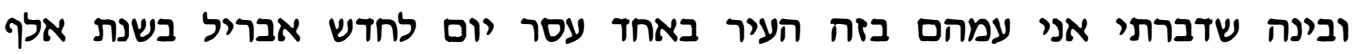
ושש מאות וששה עסר שני שנים עמחם לנולד משחנוח העיר ביאור גואן אלבאריץ די פריאה ושרת עסר שנים

En los fols. 513-519 se encuentra la censura de Alonso Sánchez, catedrático de hebreo de la universidad de Alcalá y uno de los censores que se pronunció en contra de la paráfrasis de Andrés de León, la respuesta de éste a dicha censura y la réplica de Alonso Sánchez. En el fol. 519r éste previene a los jueces contra «el hombre en cuya boca hay dolo, del lobo disfrazado con piel de cordero, raposo en las viñas", y, aunque confiesa su deseo de no hablar mal del padre Andrés, "porque él es mejor y más justo que yo", acaba

11 Cf. nota 4. 
reconociendo no creer que la sabiduría del susodicho provenga de Yahweh 12:

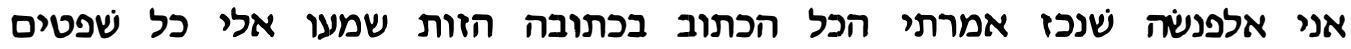

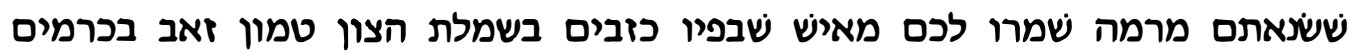
שועל: לא חפץ אני לומר רע על אבד מב ארי כי הוא טוב וצדיק ממני אף כי חי חכמתו לא מיהוה חשבתי.

En cuanto a las objeciones de Andrés de León contra la Biblia Regia, Jones ha resumido en tres puntos las veintidós de carácter general y que aluden a las cuestiones escriturarias más polémicas del momento, y en especial a la edición de Arias Montano: corregir o no los textos originales para acomodarlos a la Vulgata; conveniencia o no de expurgar la paráfrasis caldea; problemas derivados del caute legatur que se mandó añadir a la paráfrasis de la Biblia Regia en el Índice de $1612^{13}$.

Como ilustración de estas censuras nosotros hemos seleccionado algunos ejemplos concretos de carácter filológico acerca de la paráfrasis caldea, todos ellos tomados del manuscrito 503, en los que se recogen críticas, de la naturaleza más diversa, sobre los procedimientos filológicos de Andrés de León.

Así, en la pág. 682, se cierra la lista de pasajes en los que «el padre Andres de Leon quiere mudar o muda porque estando citados en el nuevo testamento no los paraphrasea el paraphraste en el sentido que Christo mismo o sus apostoles los citan». Por ejemplo, a propósito de Zacarías 11,12 (pág. 681):

"Et dixi eis, si rectum est in oculis vestris, facite voluntatem meam; si non, sinite. et fecerunt voluntatem meam viri ex parte [traducción latina de la paráfrasis caldea según la Regia]. el padre a.d.L. mudando el texto como suele $\mathrm{i}$ como no admite la lengua dize. et dixi eis, si rectum est in oculis vestris, facite voluntatem meam; sinon, sinite. et fecerunt aestimationem meam triginta argenteis. citase Math. 27»;

como se ve, la última frase de la traducción latina del Targum de

\footnotetext{
${ }^{12}$ La censura de Alfonso Sánchez editada por J. A. Jones figura en el fol. $93 \mathrm{r}$ de este mismo manuscrito. El colofón aquí transcrito aparece en el fol. 519r.

13 J. A. JONES, «Las advertencias», págs. 332-337.
} 
Andrés de León está adaptada, sin ningun fundamento textual, a Mateo 27,9, que, a su vez, es cita de Zacarías 11,13.

En las págs. 713-719 se recogen «los lugares en que muda algo el padre Leon por quitar algunos errores o disparates»; por ejemplo, en la pág. 719, comentando el Salmo 50:

"muda el padre Andres de Leon en el verso 10 las palabras de bovem accubantem $\mathrm{i}$ en el 11 el gallus silvestris $\mathrm{i}$ en el 13 et sanguinem hircorum non fuderunt sacerdotes que ni se pueden mudar como el las muda ni despues de mudadas hazen sentido ni importan i no considera que el paraphraste va acomodando todo el salmo al juizio final al modo que los judios lo imaginan i segun su sentimiento".

En las págs. 741-777 se reseñan algunos «lugares en que el padre Andres de Leon quita el nombre de la lei mudando las letras o quitando algunas o añadiendo otras i substituyendo otra voz que ni signifique lo que el piensa ni sea chaldea»; estas páginas van precedidas (pág. 740) del siguiente comentario:

"uno de los nombres que el padre Andres de Leon muda es el de la lei i por אוריתא traduce illuminatio lo cual no se puede traducir como se prueva en la plana 287. i demas de esto no se evita el inconviniente porque el padre Andres de Leon quita el nombre de la lei por parecerle judaismo de la paraphrasis».

Efectivamente, en la pág. 287 encontramos un comentario más explícito de la crítica, donde se escribe a propósito del Salmo 45,10:

"Quo tempore stabit liber legis in latere dexterae tuae [traducción latina de la paráfrasis de la Regia]. Leo vertit Quo tempore stabit portus illuminationis in latere dexterae tuae 790 significare licet rarissime portum, terminum, stationem non nego sed אוריתא significare unquam illuminationem pernego nam a radice hebraea luxit illuxit nec verbum chaldeum habemus nec nomen ullum quod lucem aut illuminationem significet imo pro hebreo מאור luminare et similibus chaldaei נהורא aut aliis utuntur. a hebreo vero ארות praesepia chald. אוריא praesepia, nec ullum simile habent quod illuminationem significet".

En las págs. 777-787 se tratan «Los lugares en que el padre 
Andres de Leon por quitar el nombre de captividad dispersion o transmigracion, o el de congregacion o reduccion o otros semejantes pone mudando las letras alguna voz que no signifique nada»; por ejemplo, a propósito de Isaías 52,12 (pág. 779), donde la traducción latina del Targum en la Regia dice «quoniam ductor erit Dominus ante vos, et congregaturus est captivitatem vestram deus israel", Andrés de León, de nuevo sin fundamento textual, corrige:

"Quoniam non in conturbatione ----- ante vos, et ducet ad propositum spem vestram deus israel»;

adviértase la sustitución de גלותכון, "captivitatem vestram", por «spem vestram".

En las págs. 789-807 figuran "Los lugares en que el padre Leon muda por conformar la version del paraphraste con la vulgata"; por ejemplo, en la pág. 789, respecto a Rut 3,1 (hebreo 2,23), frente a la traducción latina del Targum, según la Regia («et sedit cum socru sua»), Andrés de León propone

"et reversa est ad socrum suam»,

que coincide totalmente con el texto de la Vulgata ${ }^{14}$.

En las págs. 825-827 se analizan "Los lugares en que muda el texto o la version por hacerles dezir algun misterio de nuestra santa fee»; por ejemplo, en la pág. 825, en el Salmo 68,12 (Vulgata 67,12), cambia la traducción de la Regia ("Verbum Domini dedit verba legis populo suo, verum Mosse et Aharon euangelizabant Verbum Dei coetibus israelis») de la forma siguiente:

«Verbum Domini dedit verba legis populo suo, verum Messias et piscatores euangelizabant Verbum Dei coetibus israelis».

Éste es un ejemplo claro de la migración de un texto bíblico, desde el original hebreo «las albriciadoras», pasando por la paráfrasis del Targum, «Moisés y Aarón», para llegar, con Andrés de León, al

\footnotetext{
14 También falló en muchas ocasiones en tal adecuación, como se desprende de la crítica consignada en la pág. 324: «Pero lo que mas muestra su gana de mudar es que quita en muchos lugares lo que esta en la regia i es conforme a la vulgata i pone otro significado que hallo en el vocabulario»; una acusación similar aparece en la pág. 801.
} 
"Mesías y sus apóstoles», de forma que el texto aluda a «algun misterio de nuestra santa fee». En la pág. 344 se critican filológicamente los procedimientos que pudieron llevar a Andrés de León a traducción tan peregrina: transformar el משיח משה arameo en siendo así que en arameo la palabra utilizada para Mesías es משיחא; y el אהרין caldeo en interpretándolo como 'pescadores', pese a que en arameo אהרי no significa 'pescadores', sino 'nasa' '15.

Algunos de los pasajes hasta ahora comentados se circunscriben al ámbito de la "controversia», aunque se refuten con argumentos de crítica textual; veamos algunos ejemplos más, sin connotaciones ideológicas, pero no menos ricos en observaciones lingüísticas; así, en la pág. 285, comentando 3 Reyes (1 Reyes) 19,19:

«de eliseo, et ipse (ait paraphrastes) praeerat duodecim iugis boum

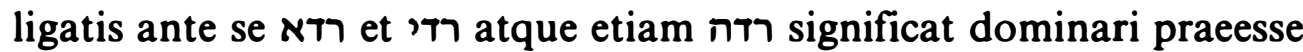
subigere castigare... hoc igitur in loco Montanus vertit Eliseum praeesse duodecim iugis boum, Leo tamen vertit arare. utrumque enim verbum hoc significat sed cum idem sit sensus nec vulgatae sacrae repugnet imo eam explicet, aptius et rectius vertitur praeesse quam arare. Eliseus enim non poterat arare duodecim iugis boum praeesse tamen arantibus ipse etiam arans optime poterat";

no se critica la opción de Andrés de León, puesto que la raíz aramea admite la interpretación de su paráfrasis, pero sí que, por seguir la Vulgata, prefiera el absurdo de poner a Eliseo arando con doce yuntas simultáneamente, en vez de que, arando con una, estuviera al frente de las demás.

En la pág. 343, acerca del Salmo 50 (hebreo 49),11 se objeta:

"et gallus sylvestris cantat coram me [traducción latina de la paráfrasis caldea de la Regia]. Leo et exultatio delecta vel evidens vel manifesta campi iubilat coram me. Chald. in regiis sic ותרננול ברא

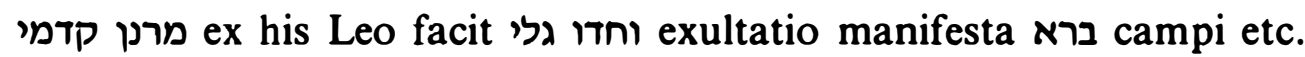
חדות manifestum, fatemur frecuentius

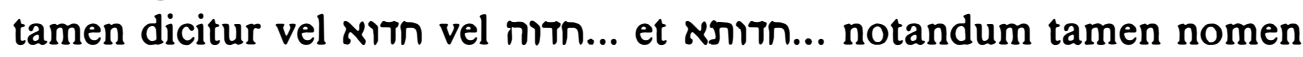
hoc esse foeminini generis ut constat ex his locis et aliis quare non

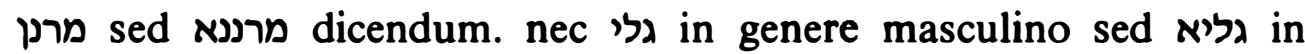
foeminino";

${ }^{15}$ Cf. E. Castellus, Lexicon Heptaglotion, Londres 1686, pág. 52. 
es decir, Andrés de León rompió en dos la palabra תרנגול (gallo), transformándola en וחדי y גל מדו no se discute que las acepciones por él aducidas de las dos palabras resultantes ("exultatio manifesta») sean erróneas ${ }^{16}$-aunque no nos parece lícito, al menos en crítica textual, partir en dos un gallo-, pero sí se critica la falta de concordancia entre la palabra que pasa a ser sujeto femenino y el participio que le sigue, masculino.

Ésta es una breve - si tenemos en cuenta el volumen de los legajos utilizados: 582 fols. el ms. 502, 829 págs. el ms. 503muestra de la polémica suscitada por el proyecto de Andrés de León de editar una nueva paráfrasis caldea.

Después de tres años de estudios, informes, censuras y comparecencias, el claustro de la universidad de Alcalá celebró sesión el 3 de septiembre de 1618. Oídos los testimonios a favor y en contra del proyecto de Andrés de León, se procedió a la votación, con el resultado de cuatro votos a favor del mismo y cinco en contra, prohibiéndose en consecuencia la impresión de la nueva paráfrasis ${ }^{17}$.

Los textos críticos que hemos citado estarían escritos por o basados en "Las advertencias» de Pedro de Valencia y Juan Moreno Ramírez, quienes refutaron allí las tesis de Andrés de León, no sólo como críticos, sino también como discípulos y amigos de Arias Montano

«a quien nosotros tenemos mui grandes obligaciones i respetamos su memoria como de maestro, señor i padre, y assi nos tenemos por obligados a su defensa la cual nos movio a mostrarnos parte i pedir que no se diesse licencia para la impresion sin que nosotros fuessemos oidos" ${ }^{18}$.

El tiempo pareció darles la razón: la Biblia Regia se reprodujo literalmente en la Políglota de París, y Arias Montano ha pasado a la historia no sólo como el mejor biblista y orientalista de nuestro pasado, sino como buen letrado, gran teólogo y hombre prudente y conciliador ${ }^{19}$.

${ }^{16}$ Cf. E. Castellus, Lexicon Heptaglotton, pág. 1133 y M. Jastrow, A Dictionary of the Targumim, the Talmud Babli and Yerushalmi, and the Midrashic Literature, New York 1967, vol. I, pág. 248.

17 Cf. J. A. JONES, “Censuras», pág. 341.

18 B. N., ms. 502, fol. 501r-v.

19 Cf. E. Fernández Tejero, "Benedicti Ariae Montani... De Mazzoreth ratione atqve vsv", en E. J. Revell (ed.), VIII Congress of the International Organization for Masoretic Studies, 1990, 65-70, 65. 
Pedro de Valencia y Juan Moreno Ramírez continuaron brillantemente en el siglo XVII la tradición filológica del siglo XVI y sus conocimientos de las lenguas hebrea, caldea, griega y latina no desdicen de los de su maestro.

Las intrigas de Andrés de León no acabaron con la censura del claustro de la universidad de Alcalá. En 1628, Guy-Michel Le Jay, consejero de Estado del rey de Francia y editor de una nueva Políglota, la de París —en la que pretendía reeditar la Biblia Regia de Arias Montano, con inclusión del Antiguo Testamento siriaco y árabe con traducción latina y del Pentateuco samaritano con traducción latina- envió a Andrés de León unos pliegos del tomo I, cuya impresión había comenzado en el mes de marzo, recabando su opinión sobre el proyecto; es evidente que ignoraba la decisión de la universidad de Alcalá. Andrés de León le respondió el 29 de julio del mismo año, criticando

«los descuidos que se notan en ésta [en la Regia] y dandole cuenta de lo que él tenía trabajado para hacer una nueva edicion de la Polyglota" ${ }^{20}$.

La carta no obtuvo el eco deseado ante Le Jay pues consta que en los cinco primeros volúmenes de la Políglota de París se imprimieron íntegramente los cinco primeros volúmenes de la Regia, con un prefacio no paginado de Le Jay y otro de J. Morin sobre el Pentateuco samaritano.

La edición de la Políglota de París fue de lo más accidentada pues el volumen IX no apareció hasta mayo de 1655 , fecha en la que ya había comenzado a imprimirse la Políglota de Londres (16541657) - más cómoda de manejar y menos costosa-, a cargo de $B$. Walton, publicada por suscripción popular y patrocinada por Cromwell. Esta Políglota inglesa bloqueó la difusión de la de París y Le Jay acabó completamente arruinado ${ }^{21}$. El mal sino de la Políglota

20 J. Rodríguez de CASTro, Biblioteca Española, I, pág. 531; el encabezamiento de la carta (ibid., pág. 532) es un exponente claro de la postura de Andrés de León con respecto a la Regia: «Regia Biblorum Antuerpiensum editio quae magnam partem extat in Bibliis Parisiensibus, castigatur in plurimis locis, Paraphrasis Chaldaica ad antiqua exemplaria M.SS. reformatur, specimen novae Editionis Bibliorum Antuerpiensium correctioris, cui Biblia Pontificia non vero Regia nomen futurum erat" [la cursiva es nuestra].

${ }^{21}$ F. Vigouruox, Dictionnaire de la Bible, v, cols. 520-522. 
de París se prolonga hasta la actualidad, pues en el volumen VI de la colección "Bible de tous les temps", sobre el siglo XVII francés, no se le dedica ningún estudio y tan sólo se la menciona de pasada al hablar del Pentateuco samaritano o de los hebraístas cristianos ${ }^{22}$.

Tampoco fue muy feliz, al parecer, el final de Andrés de León. Según el testimonio del padre F. García de Palacios en su Ateneo Minorita, pasó el último año de su vida en riguroso retiro, sin salir apenas de su celda; y, de acuerdo con el padre Villafranca, quemó todos sus papeles antes de morir ${ }^{23}$.

\section{RESUMEN}

Como continuación de la polémica surgida en el siglo XVI respecto a la Biblia Regia de Arias Montano, el siglo XVII es testigo de una nueva controversia, personificada en Andrés de León versus Pedro de Valencia y Juan Moreno Ramírez. Basándose en los documentos existentes (mss. 502 y 503 de la Biblioteca Nacional de Madrid), los autores analizan los argumentos filológicos esgrimidos por una y otra parte en favor o en contra de una nueva versión de la paráfrasis caldea de la Biblia Regia, a la luz de algunos de los pasajes más controvertidos de las correcciones propuestas por Andrés de León. El estudio refleja y confirma el superior bagaje filológico de Arias Montano y sus discípulos frente a sus adversarios.

\section{SUMMARY}

As an extension of the polemic arisen in the 16th century on Arias Montano's Biblia Regia, the 17th century witnesses a new controversy, of which the main protagonists were Andrés de León on the one hand, and Pedro de Valencia and Juan Moreno Ramírez on the other. On the basis of the extant documents (MSS 502 and 503 of the Biblioteca Nacional of Madrid) the authors analyse the philological arguments brandished by both fronts, for and against a new version of the Chaldean paraphrase of the Biblia Regia, in the light of Andrés de León's corrections in some of its most disputed passages. This study confirms the superior philological competence of Arias Montano and his disciples in face of their opponents.

22 J.-R. Armogathe, Le Grand Siècle et la Bible, París 1989; cf. págs. 64, 66 y 91.

${ }^{23}$ J. Rodríguez de CASTro, Biblioteca Española, I, pág. 530. 